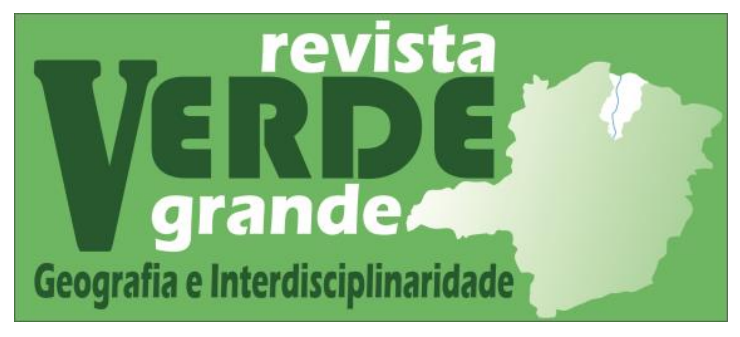

\title{
REFLEXÕES CONCEITUAIS NO/DO ESPAÇO LIVRE PÚBLICO CONTEMPORÂNEO: DISCUSSÕES ENTRE SEUS USOS NAS CIÊNCIAS GEOGRÁFICA E ARQUITETÔNICA
}

\section{Conceptual reflections in/from the contemporary public free space: discussions between their uses in the geographic and architectural sciences}

\author{
Christiana de Castro Nogueira Alcântara ${ }^{1}$ https://orcid.org/0000-0003-4304-8824 \\ Carlos Alexandre de Bortolo ${ }^{2}$ https://orcid.org/0000-0002-9539-1176
}

\footnotetext{
${ }^{1}$ Arquiteta e Urbanista, Mestre em Geografia pelo Programa de Pós-Graduação em Geografia - Universidade Estadual de Montes Claros. Docente do curso de Arquitetura de Urbanismo da UNIFIPMOC. E-mail: christiana.fipmoc@ gmail.com

2 Doutor em Geografia pelo Programa de Pós-Graduação em Geografia da Universidade Estadual de Maringá (UEM). Próreitor adjunto da Pós-Graduação da Unimontes e Professor efetivo do Departamento de Geociências e do Programa de Pósgraduação em Geografia da Unimontes. E-mail: carlos.bortolo@unimontes.br
}

\section{Resumo}

A Geografia e a Arquitetura são duas áreas de conhecimento que voltam seus estudos para o mesmo objeto: o espaço. A fim de compreender os espaços livres públicos na cidade contemporânea, adotouse, como ponto de partida, o modo como cada ciência distingue epistemologicamente o conceito de espaço. O objetivo foi de compreender, por uma visão mais abrangente, compreender o modo como os espaços públicos livres se formam e conformam nas cidades, por suas dinâmicas peculiares. Alicerçada em uma abordagem integrada, a análise sob o ponto vista de dois campos de conhecimento foi importante, por ampliar e aprofundar o conhecimento sobre a conformação do espaço livre público na atualidade. Considerando que o espaço arquitetônico é um vazio e o espaço geográfico é a possibilidade de ação e relação entre objetos e coisas no tempo, chega-se à essência da produção espacial: o lugar. Nota-se, portanto, a importância de uma reflexão das duas ciências para a análise e construção dos espaços públicos na cidade contemporânea.

Palavras-chave: Espaço. Espaço Público Livre. Geografia. Arquitetura.

\begin{abstract}
Geography and Architecture are two areas of knowledge that focus their studies on the same object: space. In order to understand public open spaces in the contemporary city, the way in which each science epistemologically distinguishes the concept of space was adopted as a starting point. The objective was to understand, through a more comprehensive view, to understand the way free public spaces are formed and conformed in cities, due to their peculiar dynamics. Based on an integrated approach, analysis from the point of view of two fields of knowledge was important, as it broadened and deepened the knowledge about the conformation of public free space today. Considering that the architectural space is a void and the geographical space is the possibility of action and relationship between objects and things in time,
\end{abstract}


the essence of spatial production is arrived at: the place. It is noted, therefore, the importance of a reflection of the two sciences for the analysis and construction of public spaces in the contemporary city.

Keywords: Space. Public free space. Geography. Architecture.

\section{Introdução}

Ao longo da história, o homem promoveu diversas alterações no espaço de modo a facilitar sua sobrevivência. Em busca de satisfazer suas necessidades mais imediatas, fez com que a natureza, aos poucos, fosse sendo alterada por suas ações, transformando o meio natural em meio geográfico e, por conseguinte, constituiu espaços habitáveis como as cidades.

Pode-se dizer que na década de 1970 o conceito de espaço se tornou alvo de críticas diretas por parte dos geógrafos e arquitetos, exigindo esclarecimento de algumas distinções epistemológicas que se confundem entre esses campos de saber. (SANTOS, 2006; MALARD, 2006).

Essa tentativa exige um breve retorno histórico, pelo qual se percebe a clara conexão entre as disciplinas Geografia e Arquitetura: momento em que o homem, ainda primitivo, relaciona-se com o espaço, a fim de satisfazer, não só suas necessidades fisiológicas, como também seus desejos e anseios.

Ao buscar abrigo, o homem primitivo trabalhou com a produção do espaço geográfico adjacente ao seu corpo, e, paralelamente, com a execução de um microclima que relacionava técnicas construtivas combinadas a ofícios e práticas existentes.

O período primitivo caracterizou-se, portanto, por um desenvolvimento tecnológico rudimentar que se direcionava apenas à produção de um microclima. Essa técnica auxiliou na construção de barreiras que ajustavam o clima imediato, além de configurar ambiências que orientavam um programa de funções e arranjos, definindo os lugares. (ROCHA, 2002).

Uma visão resultante dessas considerações permite compreender que há um processo de melhoria substanciada que ordena peças, lugares e objetos que se dispõem programadamente a partir de orientações coerentes entre natureza e necessidade humana, configurando um novo espaço geográfico.

O espaço urbano é, portanto, formado por um conjunto de objetos e ações ${ }^{1}$ que compõem o desenho urbano definido por cheios e vazios que estruturam visualmente as cidades. Nesses

\footnotetext{
${ }^{1}$ Conceitos utilizados por Milton Santos para definir a dinâmica espacial no livro "A natureza do Espaço" (2006)
} 
vazios, chamados de espaços livres públicos ${ }^{2}$, há a possibilidade do encontro, da permanência e da socialização, sendo essenciais enquanto espaços de cidadania, de identidade e de lazer.

A definição de espaço público, oriunda do período Moderno, ainda é bastante utilizada, principalmente por aqueles que o projetam ou o gerem. Esse período aliou elementos históricos, políticos e identidades ao conhecimento científico, compondo um único discurso, que ressaltou o pertinente funcionamento do espaço público como dependente da racionalidade e equilíbrio entre a sociedade e o Estado. Por esse viés, homogeneizou culturas, identidades e diferentes espaços como uma mesma estrutura, a fim de estipular princípios para a vida em sociedade, numa escala mundial.

À medida que esse discurso se fortalece, coloca-se à prova a produção social do espaço, devido aos problemas existentes na unidade e controle das complexidades espacializadas pela vida urbana, passando o modo de produção capitalista a ser o principal intensificador dessas mudanças.

A Revolução Industrial, que marcou o período Moderno, ocasionou significativas alterações para as cidades, mantendo essa disfunção até a atualidade, com uma das principais invenções: o automóvel.

Nota-se que o urbanismo que surgia por essa vertente, preocupava-se apenas com medidas técnicas pautadas no conhecimento científico quantificável e exato, desprezando a história pela qual a sociedade surgiu.

Sobre a nova política urbana que se estabelecia, ordenava o território através de uma geometria simples e, por certo tempo, conseguiu acalmar as tensões sociais. No entanto, Colosso (2016) afirma que tal política não passou apenas de uma ilusão porque um método racionalizado para lidar com uma realidade, não é capaz de enfrentar a complexidade do fenômeno urbano.

Ao se considerar o espaço sob a óptica da racionalidade, o fato de que ele é socialmente produzido, se afasta de possíveis análises e, assim, após meados do século XX, fica evidente a formação socioeconômica do espaço capitalista.

O significado social que antes possuía o espaço público se perde, sendo pensados apenas pela utilidade e função específicas determinadas por e para classes dominantes. Além do mais, havia a prioridade de ser planejado para o automóvel e circulação de mercadorias. (ALMEIDA, 2006)

\footnotetext{
${ }^{2}$ Definição de espaço público livre utilizada por Magnolli, 2006, p. 179: "O espaço livre é todo espaço não ocupado por um volume edificado (espaço-solo, espaço-água, espaço-luz ao redor das edificações a que as pessoas têm acesso)".
} 
Nas décadas de 50 e 60 a crença era de que as vias possibilitassem efeito benéfico à cidade, pois reduziria congestionamentos e trariam maior segurança. No entanto, essa solução trouxe graves problemas ao defender quadras extensas, poucas travessias, degradação e consumo do espaço urbano e falta de qualidade para as pessoas. Eram espaços que levavam nada a lugar nenhum. (JACOBS, 2009)

Ainda que a modernidade trouxesse grandes avanços, ao alterar a relação do homem com a cidade, acentuou e favoreceu diversos problemas, contribuindo para conflitos urbanos e, principalmente, para a volatilidade das relações sociais. No tocante ao planejamento urbano, a escala humana deixou, portanto, de ser prioridade.

Uma das maiores preocupações das sociedades atuais é garantir aos cidadãos o que é seu por direito: a cidade. Diversas cidades já apresentam uma nova visão sobre essa questão. Rompendo a lógica de um planejamento prático moderno, buscam criar espaços de maior qualidade, tanto para seus usuários, quanto para a aparência das cidades, mediante estratégias de desenho urbano e apropriação. Essa é uma realidade que evidencia a tentativa do retorno das tomadas de decisões, envolvendo a escala do homem e suas vivências na cidade.

Profissionais ligados à gestão e produção do espaço tornam-se agentes imprescindíveis nessa dinâmica de urbanização, apreciando potencialidades e abrandando ameaças que podem advir desse processo. Entende-se que espaços públicos bem planejados e projetados podem favorecer a qualidade e o bem-estar para a vida urbana e para as pessoas.

Essa realidade exige que os profissionais ligados à produção do espaço público voltem seus olhares para esses espaços, de modo a oferecer mais qualidade para as cidades e seus usuários. Deste modo, o objetivo deste estudo é clarear a importância da união de diferentes campos de conhecimento como o da geografia e o da arquitetura e urbanismo para a produção de espaços melhores.

\section{Refletindo sobre a Geografia e Arquitetura: um espaço comum}

Neste ensaio, se faz necessário debruçar sobre a compreensão acerca das várias formas que se abordam o espaço livre público perante a Geografia e a Arquitetura. Vale abarcar sobre os objetos geográficos encontrados na humanidade, sejam eles naturais e/ou sociais, em conjunto com a vida, participando de um arranjo espacial, que é a própria sociedade em movimento. (SANTOS, 2006). Logo, o conceito de espaço adquire certo abstrativismo, uma vez que “o espaço é a síntese, sempre provisória, entre o conteúdo social e as formas espaciais.”. (SANTOS, 2006, p.10). 
Corrêa (1998) completa que o objeto da geografia é a própria sociedade, viabilizando seu estudo pela organização espacial, também entendida como materialidade social.

Moreira (2007) afirma que a geografia serve para desvendar máscaras sociais. E é mediante os arranjos espaciais que se conhece o espaço. Sua organização reflete o modo como se dão as relações sociais. Com isso, afirma que o

[...] espaço é história, estatuto epistemológico sobre o qual a geografia deve erigir-se como ciência. E tal noção reside na mera constatação de que a história desenrola-se no espaço geográfico, mas, antes de tudo, de que o espaço geográfico é parte fundamental do processo de produção social e da estrutura de controle da sociedade. [...] O processo formador do espaço geográfico é o mesmo da formação econômico-social. Por isso, tem por estrutura e leis de movimento a própria estrutura e leis de movimento da formação econômicosocial. Podemos, com isso, doravante, designar o que até agora chamamos de organização do espaço por formação espacial, ou formação sócio-espacial, como propôs Santos (1978). (MOREIRA, 2007, p, 62)

Para Carlos (2017), a análise geográfica do mundo desvenda sempre o processo que constitui o espaço social, e, assim Moreira (2007) recorre à importância de se conhecer a natureza e o movimento de formação socioeconômica pelo espaço como seu objeto:

O espaço geográfico é o espaço interdisciplinar da geografia. É a categoria por intermédio da qual se pode dialogar com os demais cientistas que buscam compreender o movimento do todo da formação econômico-social, cada qual a partir de sua referência analítica. (MOREIRA, 2007, p. 63)

Dessa maneira, Santos (2006) acredita que uma formação socioespacial não pode se firmar como formação socioeconômica se não explorar a percepção do que é o espaço, reforçando sua ideia de que toda sociedade se apresenta pelo espaço produzido. Forma, função, estrutura, processo são categorias utilizadas pelo autor para essa abordagem analítica.

Falar da função é falar da forma. Essas categorias encontram-se habitualmente ligadas. Elas não se distanciam da estrutura social e econômica, considerada a base que as justifica. Se a estrutura é a base para as manifestações sociais, deve-se concluir que se altera constantemente, identificando-se como processo, que, conforme Bortolo (2015, p. 27) “[...] é dinâmico, ou seja, processa e é processado, modifica e é modificado, é ao mesmo tempo resultado e condição da história.".

Assim, forma, função, estrutura e processo, este último sinônimo de tempo, quando considerados em conjunto impedem a compreensão superficial e 
descritiva dos fenômenos. Essas categorias constituem uma base forte que auxilia o geógrafo na leitura e interpretação da realidade. Importante devido à relação entre as dimensões econômicas, sociais, culturais e políticas presentes na produção, usos e apropriações dos espaços públicos na atualidade. (BORTOLO, 2015, p. 28)

A forma referida por Santos (2006) não deve ser confundida com a forma arquitetônica, que, embora componha o espaço geográfico, apresenta uma autonomia que não se encontra naquela. Santos (2006) se refere ao espaço social - uma representação que pode ser materializada pela espacialização arquitetônica, mas que transmite valores específicos de determinada sociedade. Assim, o que Santos (2006) propõe é algo desprendido da autonomia que se encontra no objeto arquitetônico e que configura o espaço geográfico.

Apesar da autonomia em si mesmas, as formas arquitetônicas são consideradas apenas aparências, ou seja, aspectos visuais da arquitetura que não representam a complexidade do objeto arquitetônico. Malard (2006) explica que a aparência é uma descrição visível do pensamento para o mundo, e sua simples descrição, assim como na Geografia, não configura a essência do objeto do campo disciplinar.

Cabe, logo, uma definição do que é arquitetura. Mallard (2006) afirma que arquitetura é a aparência que incorpora lugares e remete ao significado. Comungando as ideias de Santos (2006), uma análise de um espaço passivo não teria grande valia e, desse modo, o lugar arquitetônico é constitutivo da existência humana, faz parte da essência do ser, já que “(...) a existência humana tem uma dimensão espacial que é parte da própria experiência do homem no mundo, pois todas as ações humanas ocorrem no espaço.”. (MALARD, 2006, p.26).

O problema dessa discussão encontra-se no reconhecimento do espaço público proposto e um método adequado para sua análise. Sendo assim, como compreender esse espaço? Como analisá-lo? Como defini-lo nestas duas ciências?

Espaço e tempo são vistos como produtos sociais, não podendo ser generalistas ou universais; e somente por meio de uma sociedade específica, em um contexto específico, é que poderão ser explicados. Isso implica em uma análise que considera os jogos de poder e conflitos aliados às diversidades sociais de cada contexto, fato que confirma o espaço socialmente produzido.

Bortolo (2015, p. 26) afirma:

Deste modo, as formas e objetos distribuem-se no espaço de maneira temporal e espacialmente diferenciada, apresentando a continuidade/descontinuidade, ou seja, formas e objetos pretéritos convivem com conteúdos presentes e futuros e vice-versa, conteúdos pretéritos, não atualizados, convivem com 
formas e objetos novos e/ou renovados. Estas formas-conteúdo por corresponderem padrões cujas funções são dadas pelo modo como se articulam e se organizam as instâncias e as dimensões da sociedade como um todo (estrutura), são compreendidas na totalidade em movimento (espaçotemporal) da qual fazem parte, totalidade esta que pressupõe ação e mudança (processo).

Considerando que a Geografia observa e estuda os meios físicos e a relação com o habitat humano, nota-se uma convergência entre os conhecimentos geográficos e arquitetônicos, ao se evidenciar que as duas ciências trabalham com e no mesmo objeto, o espaço. No entanto, enquanto a geografia trabalha com a sociedade, a arquitetura trabalha com o lugar que a sociedade cria e no qual se reconhece.

Considerando que o espaço está em um constante processo de transformação aliado às práticas sociais, é inegável que influenciará diretamente nos modos de uso e ocupação do espaço geográfico, à medida que a arquitetura é produzida e materializada pelas diversas espacializações.

Desse modo, estudar o espaço livre público implica analisar não somente suas estruturas físicas, o que acarretaria uma análise por demais simplista, mas principalmente as relações que contribuíram para sua existência e as que contribuem para sua permanência ou não.

A relação torna-se simples: o espaço geográfico é essencial para a existência do lugar arquitetônico que configura o espaço geográfico, mediante processos incessantes ao longo da história.

\section{Espaço livre público: conceitos e sua importância social na contemporaneidade}

Compreender o conceito de espaço e espaço livre público, como apresentado na primeira seção deste ensaio, amplia as possibilidades para se trabalhar esta temática. Sabe-se que a construção dos significados da organização espacial acontece socialmente mediante a relação entre as práticas e os objetos. Esse pensamento se originou em Lefebvre (1991), o primeiro a romper com a ideia geral de espaço independente das relações. Logo, não há possibilidade de uma análise epistemológica do espaço a partir dele, visto que é produzido socialmente e, por isso, não existe em si mesmo.

Para essa compreensão, Lefebvre (1991) apresenta três dimensões que se conectam dialeticamente: o espaço concebido, o vivido e o percebido. Por espaço concebido, entende-se o espaço das representações. Quanto ao vivido e ao percebido, entende-se, respectivamente, 
como espaço das práticas sociais, e representações. Desse modo, verifica-se que a percepção de Lefebvre (1991) sobre o espaço está ligada a três dimensões: a física, a mental e a social.

Quando o espaço social deixa de se confundir com o espaço mental (definido pelos filósofos e pelos matemáticos), com o espaço físico (definido pelo práticosensível e pela percepção da "natureza"), ele revela sua especificidade. Será preciso mostrar que esse espaço social não consiste numa coleção de coisas, numa soma de fatos (sensíveis), nem tão somente num vazio preenchido, como uma embalagem, de matérias diversas, que ele não se reduz a uma forma imposta aos fenômenos, às coisas, à materialidade física. O caráter social do espaço, afirmado aqui como prévia (hipótese), será confirmado durante a exposição. (LEFEBVRE, 1991, p. 36)

Ao introduzir sua teoria de produção do espaço, Lefebvre (1991) une primorosamente as categorias espaço e cidade, permitindo que os processos sociais possam ser analisados por diferentes modos.

As relações espacializadas ocupam o espaço geográfico e criam objetos mais complexos, como os espaços livres públicos que se estruturam em formas distintas nas cidades, as quais, por sua vez, apresentam diversos significados conforme usos e apropriações que usuários estabelecem e que dão sentido às suas vidas. Logo, são percebidas, construídas e reconstruídas de maneira coletiva e individual na contemporaneidade.

Carlos (2017) aponta que o espaço geográfico é produto, condição e meio para que a sociedade se realize, sendo reproduzido por um processo histórico ininterrupto da constituição humana. Por conseguinte,

[...] a noção de cidade ganha uma nova amplitude revelando-se em sua historicidade, aparecendo como categoria central de análise revelando a materialização do processo histórico de produção do espaço geográfico. Assim do mesmo modo que em cada momento da história se produz um espaço, este revela, em cada momento histórico, uma cidade. (CARLOS, 2017, p.9)

Como Lefebvre (1991), Carlos (2019) acredita que as relações sociais existem a partir do momento em que produzem o espaço efetivamente em lugar e tempo específicos, marcando a duração da ação, conferindo a apropriação que constrói o ser humano e dá identidade. Esse processo revela persistência e transformações, aparecendo o espaço como meio e produto da reprodução social.

Rolnik (2012) define a cidade, portanto, como um ímã: 
Isto mesmo, a cidade é, antes de mais nada, um ímã, antes mesmo de se tornar um local permanente de trabalho e moradia. Assim foram os primeiros embriões de cidade de que temos notícias, os zigurates, templos que apareceram nas planícies da Mesopotâmia em torno do terceiro milênio antes da Era Cristã. (ROLNIK, 2012, p. 13)

O lugar de cerimônias já correspondia a uma transformação no modo como o homem se relacionava com o espaço ao seu redor. Assim, a tectônica utilizada para a construção dos templos possibilitava a materialização de formas imaginadas, o que permitiu a criação de ambientes "[...] conforme os desígnios humanos." (ROLNIK, 2012, p. 14). Rolnik (2012) compara essa percepção de cidade ao ato da escrita, que é o modo de registrar e eternizar ideias.

Serpa (2004) conceitua o espaço livre público como espaço de ação política, ou pelo menos, como espaço para a possibilidade dessa ação na atualidade.

Partindo dessa ideia, Indovina (2002) entende que o espaço livre público é tido por excelência o espaço da/na cidade, constituindo uma característica essencial para que elas sejam reconhecidas e identificadas. Sendo elementos de identidade urbana, configuram lugares por meio de símbolos, socialização, escritas, encontros e manifestações sociais, culturais e políticas.

O espaço público deve ser considerado fundador da cidade (poder-se-á dizer em todas as épocas e em todos os regimes); no fundo, o espaço público é a cidade. (INDONIVA, 2002, p.119)

Borja (2003), Indovina (2002) e Jacobs (2009) reforçam o valor do espaço livre público como estruturante da cidade e a definem como o próprio espaço público. Por esse motivo, Borja (2003) não acredita que entendê-lo por um só uso seria coerente, e afirma que a cidade merece consideração do espaço público, sendo ele, por excelência, espaço da socialização. Para Gehl (2013, p. XI), "Nós moldamos as cidades e elas nos moldam.”.

Diante dessa discussão, entender o espaço livre público por uma única definição caminharia na contramão de suas complexidades, já que existem distintas e variadas ciências que o estudam. Castro (2002) coloca que o termo, por si só, revela-se intrincado, levando a pensar sobre sua colocação no singular ou no plural, ou sobre a pertinência de dizer espaço "do" público.

Essa discussão que se estende sobre os espaços livres públicos teve início principalmente a partir do século XX, e se tornou evidente tanto no meio acadêmico de diferentes áreas, quanto no meio de planejamento e gestão urbana. Cabe, por ora, entender os espaços públicos como essenciais para vida urbana. 
O entendimento de que o espaço livre público deve ser espaço para uso dos cidadãos e para realização de vida social não é recente. Sem a tentativa de um esclarecimento exaustivo, apresenta-se sucinta descrição sobre a temática.

Como meio de melhor compreender sua origem, estrutura, evolução e apropriação, a história da Arquitetura e Urbanismo coloca-se como um importante instrumento. Segundo Gehl (2013), ela mostra claramente como as estruturas e o planejamento urbano estimulam diretamente o funcionamento das cidades e o comportamento humano.

Nesse sentido, a gestão da sociedade urbana determinou os padrões que se impuseram de fora para dentro, estabelecendo a sociedade de consumo com modelos e valores que se pretendiam universais, em tempo e espaço diferenciado e desigual (CARLOS, 2017)

O choque entre o que existe e o que se impõe como novo está na base das transformações da metrópole onde os lugares vão se integrando de modo sucessivo e simultâneo a uma nova logica, aprofundando as contradições. A constituição da sociedade urbana é consequência do desenvolvimento do processo de reprodução da sociedade que produz um novo espaço e novas formas de relação entre os membros da sociedade.”. (CARLOS, 2017, p.11)

Carlos (2017) afirma que a prática social no mundo moderno evidenciou a contradição entre dois modos de produção espacial. Se, por um lado, o espaço priorizava as necessidades políticas e econômicas, por outro, visava a reprodução da vida social.

No primeiro caso a reprodução do espaço se dá pela imposição de uma racionalidade técnica assentada nas necessidades impostas pelo desenvolvimento da acumulação que produz o espaço enquanto condição da produção, revelando as contradições que o capitalismo suscita em seu desenvolvimento o que impõe limites e barreiras a sua reprodução. No segundo caso a reprodução da vida na metrópole se realiza na relação contraditória entre necessidade e desejo; uso e troca; identidade e nãoidentidade; estranhamento / reconhecimento que permeiam a prática sócioespacial. (CARLOS, 2017, p.15)

Nas duas vertentes, o espaço adquiriu sentido, finalidade e configuração diferenciados. A metamorfose presenciada nas metrópoles de mercantilização do solo urbano delineou a tendência dos modos de apropriação do espaço à submissão ao mundo da mercadoria, ocasionando o esvaziamento das relações sociais e do conteúdo das práticas sócioespaciais. O espaço tornou-se amnésico e efêmero, definindo novas relações sociais em relação ao espaço-tempo na metrópole. (CARLOS, 2017) 
Quanto aos espaços livres públicos, o significado que antes possuíam se perdeu, sendo pensados apenas pela utilidade e função específicas, determinadas por e para classes dominantes. (ALMEIDA, 2006)

Nas décadas de 50 e 60, a crença era de que as vias possibilitassem efeito benéfico à cidade, pois reduziria congestionamentos e trariam maior segurança. No entanto, essa solução trouxe graves problemas ao defender quadras extensas, poucas travessias, degradação e consumo do espaço urbano e falta de qualidade para as pessoas. Como disse Jacobs (2009), eram espaços que levavam nada a lugar nenhum. Nota-se, portanto, que o espaço não prioriza as pessoas e seus cotidianos, configurando-se esvaziado das relações sociais.

\section{Os desafios de pensar no/do espaço livre público na cidade contemporânea e seus conceitos: à guisa de conclusões}

Foi na cidade moderna que nasceu a dicotomia entre os espaços públicos e privados, entre o indivíduo e a sociedade e as novas maneiras de produção e apropriação dos espaços públicos urbanos.

O modelo moderno de urbanismo não se limitou a suas cidades de origem, espalhando-se por diferentes pontos no mundo, inclusive no Brasil. Os espaços públicos nessa nova concepção de cidade eram vistos apenas como importantes meios de salubridade urbana e renovação de sua paisagem.

Destarte, Jacobs (2009) condenou a atenção exagerada ao tráfego de veículos e a separação funcional urbana que levavam ao esvaziamento das cidades, deixando-as sem vida. Como nunca antes visto, as cidades eram pensadas não mais como aglomerados de edifícios e espaços, mas como construções individuais e segregadas.

A renovação urbana que despreza as diversidades e usos é vista por Jacobs (2009) como algo perverso, que colocaria fim aos espaços livres públicos urbanos. Ela desprezava o funcionamento urbano com preocupações voltadas apenas às aparências e aos espaços livres públicos fora de seus contextos.

Assim, Carlos (2017) acaba por acrescentar que é a partir da reprodução espacial com a reprodução da vida na metrópole que o espaço deve ser analisado. Deve-se considerar a vida cotidiana, a ideia de projeto segundo Lefebvre, que pensa a cidade "[...] como lugar onde grupos podem se reencontrar, onde eles tenham conflitos, mas também alianças, onde eles concorram à uma obra coletiva.”. (CARLOS, 2017, p. 17) 
Além dessa questão pontuada pelos autores nesse ensaio, Jacobs (2009) acredita que a insustentabilidade econômica se expressa nesse modo de planejar junto a arquitetura novas formas de pensar o espaço livre público e seus conceitos e aplicações. É fato que, principalmente a partir da década de 60 , a dimensão humana foi constituinte esquecido do planejamento urbano, enquanto outras questões como o tráfego de veículos, ganharam destaque, como coloca Gehl (2015):

Além disso, as ideologias dominantes de planejamento - em especial, o modernismo - deram baixa prioridade ao espaço público, às áreas de pedestres e ao papel do espaço urbano como local de encontro dos moradores da cidade. Por fim, gradativamente, as forças do mercado e as tendências arquitetônicas afins mudaram seu foco, saindo das inter-relações e espaços comuns da cidade para os edifícios individuais, os quais, durante o processo, tornaram-se cada vez mais isolados, autossuficientes e indiferentes. (GEHL, 2013, p. 3)

Bortolo (2015) destaca que os problemas econômicos, sociais e políticos acabam por interferir na existência de espaços livres públicos e em seu uso limitado. $\mathrm{O}$ autor frisa que são quase inexistentes políticas públicas voltadas para a concepção de novos espaços livres públicos e, quando existem, geralmente estão ligadas a propagandas eleitorais de candidatos.

Para Gehl (2013), essa ainda é uma característica presente em quase todas as cidades, independentemente de sua situação econômica, localização ou desenvolvimento. Ela não só reduziu as oportunidades de locomoção dos pedestres, como também segregou funções sociais e culturais do espaço. A vida agitada nas cidades, a velocidade dos automóveis e a falta de segurança nas ruas contribuíram para transformar os espaços públicos, diminuindo a vida social.

Destarte, esses espaços foram, aos poucos, sendo abandonados por parte de camadas sociais, principalmente as de médio a alto poder aquisitivo, sob a justificativa de não oferecerem condições de desenvolvimento da vida coletiva e segurança. A insegurança nas ruas e a violência fizeram com que a dimensão privada do espaço se tornasse foco das atenções do planejamento urbano.

Assim, na cidade contemporânea, o espaço livre público já não mais apresenta suas características anteriores. É inegável que, na atualidade, seja influenciado pelos processos que ocorrem na sociedade e se transforme alavancado pelas redes informacionais e pela acumulação do capital que, em dimensão global, usam as cidades como espaço essencial para suas manifestações. O solo urbano assume a característica de mercadoria e faz surgir nova forma de 
estruturação espacial com a criação de novos espaços coletivos, mas que não oferecem as peculiaridades do espaço público anterior.

O desenvolvimento de novas tecnologias tem provocado profundas transformações nos diferentes usos dos espaços das cidades. Os conjuntos de relações entre as pessoas, instituições que acabam por se estabelecer muito além da escala urbana, a crescente invisibilidade e desmaterialização destas relações dos mais variados processos urbanos, aumento da fragmentação e a descontinuidade da cidade, acabam por somar elementos que passam a contribuir para a modificação ou também a diminuição de certos usos dos espaços públicos da cidade. (BORTOLO, 2015, p.64)

Mas, ainda assim, o espaço livre público apresenta-se como importante constituinte da vida urbana, junto as análises da Geografia e da Arquitetura:

A qualidade de vida de uma cidade é, e sempre será medida pela dimensão da vida coletiva que é expressa nos seus espaços públicos dispostos democraticamente pela cidade, seja no parque, na praça, na praia ou mesmo na rua. $\mathrm{O}$ espaço público de uma cidade é o lugar do lazer, do descanso, da conversa corriqueira, da livre circulação, da troca e, sobretudo, da possibilidade do encontro com o outro. (ESPAÇOS PÚBLICOS - Diagnóstico e metodologia de projeto, p.8)

Evidencia-se que as transformações ocorridas nos espaços públicos são resultantes das ações cotidianas que se materializam em diferentes realidades, como tempo histórico, relações de poder e diferentes vontades.

Portanto, o processo de produção do espaço se revela nos modos de aproximação de uma realidade social, produto modificado pela experiência no lugar, e sua relação com o mundo, relação esta múltipla de sensação e de ação, mas também de desejo e, por consequência de identificação com a projeção sobre as diferentes formas de conceber a produção do espaço público. (BORTOLO, 2015, p.65)

A tentativa da modernidade de construir um único conceito para o espaço livre público reduziu as possibilidades de compreender a sociedade e suas espacialidades por sua complexidade. Para Santos (2006), não se deve perder o rigor, mas, sim, a rigidez que limita o conhecimento.

Observa-se a importância de compreender o processo de análise a partir da formação econômica social e espacial proposta por Santos (1996) ao tentar refletir sobre o desenvolvimento, transformação e evolução das mais distintas 
formas de produção dos espaços públicos na contemporaneidade. (BORTOLO, 2015, p. 21)

Gehl (2013) aponta que agora, no século XXI, coloca-se um grande desafio para os estudiosos do espaço como a cidade. Aos geógrafos cabe a tarefa de, não só pensar o espaço, mas, principalmente, a relação espaço-tempo, considerando a sua indissociabilidade; do mesmo modo os arquitetos e urbanistas, a fim de reforçarem a criação de espaços com qualidade para pessoas e a função social da cidade para o encontro e a sociabilidade urbana.

Deste modo, o processo de urbanização atual não se firma mais no modelo industrial e passa a induzir as práticas humanas, sendo necessárias perspectivas que compreendam a questão urbana; e que compreendam além da cidade e reflitam sobre um urbano que abarque a realidade, pois a noção de produção diz respeito não apenas à produção das mercadorias, mas também à produção do próprio homem e suas relações. (CARLOS, 2007).

"A realidade urbana nos coloca diante de problemas cada vez mais complexos, que envolvem o desvendamento dos conteúdos do processo de urbanização nos dias de hoje.”. (CARLOS, 2007, p. 19).

Assim, trabalhamos neste ensaio a busca de contribuir para que se alcance a sustentabilidade teórica conceitual, no que tange o espaço livre público no âmbito social e em uma sociedade mais democrática e acessível a todos, utilizando das ideias destas ciências que se relacionam no modo de construir ideias e conceitos.

"Conquanto a cidade seja também o cenário de trocas econômicas, de produção cultural, de exibição de avanços tecnológicos, de fluxos e deslocamentos, ela é, acima de tudo, o lar da maioria da humanidade." (GEHL, 2013, p. XIII).

Deve-se, portanto, refletir sobre os espaços livres públicos nas sociedades capitalistas contemporâneas, não esquecendo as funções que são desempenhadas pelas formas. As estruturas, ao serem alteradas, modificam consequentemente as ações, os processos e os eventos que se especializam, refletindo o tempo e o espaço socialmente produzidos e evidenciando as dinâmicas nos e dos espaços atuais, tanto para a Geografia, quanto para a ciência arquitetônica contemporânea.

Considerando que a Geografia observa e estuda os meios físicos e a relação com o habitat humano, nota-se uma convergência entre os conhecimentos geográficos e arquitetônicos, ao se evidenciar que as duas ciências trabalham com e no mesmo objeto, o espaço. No entanto, enquanto a geografia trabalha com a sociedade, a arquitetura trabalha com o lugar que a sociedade cria e se reconhece. 
Se o espaço está em um constante processo de transformação atrelado às práticas sociais, é inegável que à medida em a arquitetura é produzida e materializada pelas diversas espacializações, influenciará diretamente nos modos de uso e ocupação do espaço geográfico.

Deste modo, estudar o espaço livre público implica em analisar não só suas estruturas físicas, o que acarretaria uma análise por demais simplista, mas principalmente as relações que contribuíram para sua existência e as que contribuem para sua permanência ou não.

A relação se torna simples: o espaço geográfico é essencial para a existência do espaço arquitetônico que configura o espaço geográfico através de processos incessantes ao longo da história.

\section{Referências}

ALMEIDA, A. Sustentabilidade dos espaços públicos na reabilitação de núcleos urbanos: questão das praças. Lisboa: Lisboa FAL., 2006. Disponível em: <http://www.revistas.usp.br/paam/article/view/> . Acesso em: $18 \mathrm{dez} .2018$.

BORTOLO, Carlos Alexandre de. A dinâmica dos espaços públicos de lazer em cidades da aglomeração urbana de Londrina. 2015. Tese de doutorado, Centro de Ciências Humanas, Letras e Artes - departamento de geografia, Universidade Estadual de Maringá Londrina, Paraná. 2015, 232p.

CARLOS, Ana Fani Alessandri. Espaço-tempo da vida cotidiana na metrópole. São Paulo: FFLCH /USP 2017.

CORRÊA, Roberto Lobato. O Espaço Urbano. $3^{\text {a }}$ Ed. São Paulo: Editora Ática S.A, 1998.

GEHL, Jan. Cidades para Pessoas. São Paulo: Perspectiva, 2013.

INDOVINA, F. O Espaço público-tópicos sobre a sua mudança. Revista Cidades, Comunidades e Territórios, Lisboa, Instituto Superior de Ciências do Trabalho e da Empresa (ISCTE), n.5, p.119-123, 2002. Disponível em: 〈http://www.revistas.usp.br/paam/article/view〉. Acesso em: $18 / 12 / 2018$.

JACOBS, Jane. Morte e Vida de Grandes Cidades. São Paulo: Editora WMF Martins Fontes, 2009.

LEFEBVRE, Henry. The Production of Space. Trad. D. Nicholson-Smith Oxford: Basil Blackwell, 1991.

Magnoli, M. (2006). Espaço livre - objeto de trabalho . Paisagem E Ambiente, (21), 175-197. Disponível em: <https://doi.org/10.11606/issn.2359-5361.v0i21p175-197>. Acesso em: 20 jan. 2019. 
Reflexões conceituais no/do espaço livre público contemporâneo: discussões entre seus usos nas ciências geográfica e arquitetônica

Christiana de Castro Nogueira Alcântara; Carlos Alexandre de Bortolo

MALARD, Maria Lúcia. As aparências em arquitetura. Belo Horizonte: Editora UFMG, 2006.

MOREIRA, Ruy. Pensar e ser em Geografia. São Paulo: Contexto, 2007.

ROCHA, Bruno Massara. Conceitos sobre a arquitetura primitiva e derivações. Artigo Online. Disponível em: <http://territórios.org/teoria/H_C_primitiva.html〉. Acesso em: 03 fev. 2018

RONIK, Raquel. O que é cidade. São Paulo: Brasiliense, 2012.

SANTOS, Milton. A natureza do espaço. 3 ed. São Paulo: Hucitec, 2006.

SERPA, A. Espaço público e acessibilidade: notas para uma abordagem geográfica. Revista GEOUSP - Espaço e Tempo, São Paulo, n.15, p. 21-37, 2004. Disponível em: <http://www.revistas.usp.br/geousp/article/view/123865>. Acesso em: 05 jan. 2019. 